\title{
Dielectric properties of nanosilica/low-density polyethylene composites: The surface chemistry of nanoparticles and deep traps induced by nanoparticles
}

\author{
S. Ju ${ }^{1,2}$, M. Chen ${ }^{1}$, H. Zhang 1 , Z. Zhang ${ }^{1 *}$ \\ ${ }^{1}$ National Center for Nanoscience and Technology, China, 100190 Beijing, China \\ ${ }^{2}$ University of Chinese Academy of Sciences, 100049 Beijing, China
}

\begin{abstract}
Four kinds of nanosilica particles with different surface modification were employed to fabricate low-density polyethylene (LDPE) composites using melt mixing and hot molding methods. The surface chemistry of modified nanosilica was analyzed by X-ray photoelectron spectroscopy. All silica nanoparticles were found to suppress the space charge injection and accumulation, increase the volume resistivity, decrease the permittivity and dielectric loss factor at low frequencies, and decrease the dielectric breakdown strength of the LDPE polymers. The modified nanoparticles, in general, showed better dielectric properties than the unmodified ones. It was found that the carrier mobility, calculated from $J-V$ curves using the Mott-Gurney equation, was much lower for the nanocomposites than for the neat LDPE.
\end{abstract}

Keywords: nanocomposites, insulation, silica, polyethylene (PE), carrier mobility

\section{Introduction}

Polymer nanocomposites have recently drawn great attention of scientists [1-3]. Research has shown that nanofillers can improve the dielectric breakdown strength [4], enhance the voltage endurance [5], depress the space charge formation [6] and weaken the partial discharge degradation [7] of the pristine polymers more significantly than the micro-sized fillers. These improvements are of importance to electrical insulation applications and shed light on further advancement in dielectric materials [8].

The dispersion of nanoparticles in the polymer matrix $[11,12]$ and the property of the interface between nanoparticle and polymer are regarded as key factors affecting the electric insulating properties of nanocomposites $[13,14]$. The interaction zone around nanoparticles can be considered as a 'quasi-conductive' region that partially overlaps in the nanocom- posites, as proposed by Lewis [15]; they describe the interface as the pathway, charge would be transferred between a metal electrode and a dielectric phase, which can even control the conductive properties of the latter. Furthermore, another working hypothesis, so-called 'multi-core' model has also been proposed, which divides the 'interaction zone' of polymeric nanocomposites into three layers from particle surface to matrix $[16,17]$; this model is used to illustrate several electrical performance of the polymer nanocomposites. Both the hypotheses believe that the charge dissipation in the interfacial regions could be the main reason to improve the dielectric breakdown strength and space charge suppression. To improve the properties of the nanocomposites, the fine interface characteristics of nanoparticles as well as the homogeneous dispersion are needed. The common solution is to modify the nanoparti-

\footnotetext{
${ }^{*}$ Corresponding author, e-mail: zhong.zhang@nanoctr.cn (C) BME-PT
} 
cles using coupling agents [18, 19]. Roy et al. [20] show that the vinylsilane modified nanosilicas offer XLPE a larger increase in the dielectric breakdown strength and double time to failure in voltage endurance strength, as compared to unmodified nanosilica filled materials. Using cold atmospheric-pressure plasma to modify nanosilica particles, Yan et al. [21] find that modified nanosilica/polymer nanocomposites show higher dielectric breakdown strength and extended endurance under a constant electrical stress, compared with the unmodified nanocomposites and neat polymer.

Besides the above, some other views have been proposed to explain why and how the nanoparticles affect the dielectric properties of polymer materials. Huang et al. [9] consider that inorganic particles may reduce the carrier mobility in the composite materials, thereby increasing their insulating properties. Takada et al. [10] propose a trapping model of 'induced dipole polarization'; it is proposed that the deep potential well induced by nanoparticles becomes trapping sites for carriers, which hinder the movement of carriers and avoid the space charge accumulation in the defect positions.

So far, a few researches have systematically studied the effects of different nanoparticle surface chemistry on the performances of composite materials. And this is the main goal of the present work. The dielectric breakdown strength, space charge, volume resistivity and permittivity of the $\mathrm{SiO}_{2} / \mathrm{LDPE}$ nanocomposites were measured and compared with those of the neat LDPE. The carrier mobility was evaluated from the quadratic $J-V$ curves of the samples using the Mott-Gurney equation. It is demonstrated that the space charge suppression and volume resistivity of the nanocomposites with surface-modified fillers were significantly improved, which is probably due to the lower carrier mobility in the nanocomposites.

\section{Experimental}

\subsection{Materials}

LDPE $(2220 \mathrm{H})$ with density of $0.923 \mathrm{~g} / \mathrm{cm}^{3}$ and melt flow rate of $2.0 \mathrm{~g} / 10 \mathrm{~min}$ was purchased from BASF-YPC Company (China). High purity fumed nanosilica (purity $>99 \%$ ) with the trademarks of A200, R312, R805 and R974 were obtained from Evonik Degussa AG (Germany). The nanosilicas A200 were un-surface-modified, while others were modified by vinyltrimethoxysilane, octyltrimethoxysilane and dimethyldichlorosilane, respectively, as stated by the supplier. The detailed information of the nanoparticles is listed in Table 1.

The different nanosilicas were mechanically mixed with LDPE granules at the processing temperature of $130^{\circ} \mathrm{C}$ using the HAAKE PolyLab mixer (HAAKE Rheomix600, Germany). Films of the neat LDPE and nanocomposites were prepared by a hot-press method at the temperature of $150^{\circ} \mathrm{C}$ and the pressure of

Table 1. Properties of the silica nanoparticles

\begin{tabular}{|c|c|c|c|c|}
\hline Trademark & $\begin{array}{c}\text { Average primary } \\
\text { particle size } \\
{[\mathbf{n m}]}\end{array}$ & $\begin{array}{c}\text { BET specific } \\
\text { surface area } \\
{\left[\mathbf{m}^{2} / \mathbf{g}\right]}\end{array}$ & Surface modifier & Chemical structure of surface modifier \\
\hline $\mathrm{A} 200$ & 12 & $200 \pm 25$ & - & vinyltrimethoxysilane \\
\hline $\mathrm{R} 312$ & 12 & $210 \pm 30$ & $150 \pm 25$ & octyltrimethoxysilane
\end{tabular}


$20 \mathrm{MPa}$. The prepared films were placed in a vacuum oven at $95^{\circ} \mathrm{C}$ for $30 \mathrm{~min}$, and then cooled down to room temperature to eliminate thermal history. To banish the remainder charge, the films were put between two polished copper plates in a vacuum oven at $80^{\circ} \mathrm{C}$ for $48 \mathrm{~h}$ short-circuiting.

\subsection{Characterization}

The surface chemical characteristics of the nano-silica were measured using X-ray photoelectron spectroscopy (XPS, Thermo Scientific ESCALAB 250Xi, USA) performed with $\mathrm{Mg} \mathrm{K} \alpha$ radiation. $\mathrm{C}, \mathrm{O}$ and $\mathrm{Si}$ were recorded.

The dispersion level of nanosilica in LDPE was observed using a field emission SEM (Hitachi S4800 , Japan) at $6 \mathrm{kV}$ accelerating voltage. The composite samples for SEM were fractured in liquid nitrogen and sputtered with thin gold layer.

DC (direct-current) dielectric breakdown strength of samples was measured using a dielectric strength tester (HT-50, Guilin Electrical Equipment Scientific Research Institute, China). The sample $(70 \pm 10 \mu \mathrm{m}$ thick) was placed between $6 \mathrm{~mm}$ diameter copper cylindrical electrodes and tested at a voltage ramping rate of 500 and $2 \mathrm{kV} / \mathrm{s}$ until the sample failed. The whole setup was immersed in silicone oil. Weibull distribution was employed to fit the experimental data and determine the characteristic DC dielectric breakdown strength of the samples according to the IEEE Standard 930-2004 [22].

The space charge distribution was tested by pulsed electroacoustic measurement (PEA, Harbin university of science and technology, assembled by themselves) carried out under an electrical field of $40 \mathrm{kV} / \mathrm{mm}$ for 0.5 and $10 \mathrm{~min}$ at $25^{\circ} \mathrm{C}$. The sensitivity of space charge was $0.6 \mu \mathrm{C} / \mathrm{cm}^{3}$ with spatial resolution of $18 \sim 19 \mu \mathrm{m}$. During the measurement, the sample ( $300 \mu \mathrm{m}$ thick $\times 10 \mathrm{~cm}$ long $\times 10 \mathrm{~cm}$ wide $)$ was sandwiched between an aluminum electrode and a semi-conductive polymer electrode (both $7.5 \mathrm{~cm}$ in diameter).

Dielectric properties of the composite samples were measured by a high-resolution ALPHA analyzer (Novocontrol, Germany). The film samples (1 mm thick, $20 \mathrm{~mm}$ in diameter) were placed between two gold-coated stainless steel electrodes. The permittivity and loss tangent were measured in the frequency range from $10^{-2}$ to $10^{6} \mathrm{~Hz}$ at $25^{\circ} \mathrm{C}$.

Volume resistivity, polarization current and shortcircuited current of the samples were measured

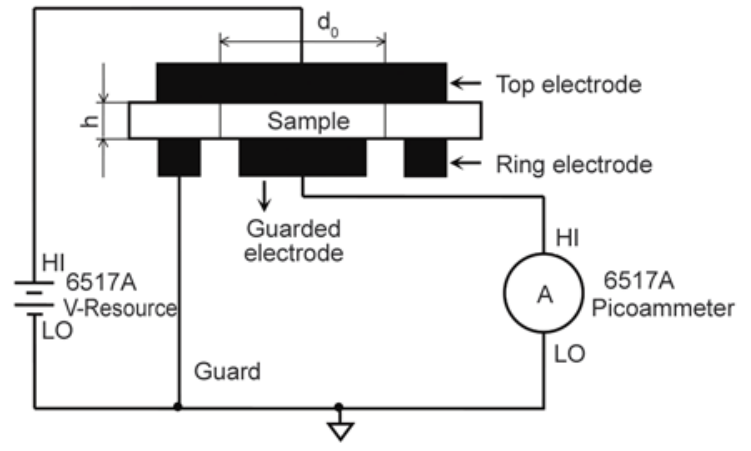

Figure 1. Experimental set-up for measuring volume resistivity and polarization current of samples

with a Keithley electrometer model 6517A. A standard three-electrode system was used, as illustrated in Figure 1, where the conductive rubber pad diameter $\left(d_{0}\right)$ is $54 \mathrm{~mm}$ and the thick of sample $(h)$ is $0.1 \mathrm{~mm}$. The volume resistivity was tested at a DC voltage of $50 \mathrm{~V}$ and the polarization current at $1000 \mathrm{~V}$. The short-circuit current was obtained by letting the upper and lower surfaces of the sample short circuit after applying $1000 \mathrm{~V}$ for five minutes [7].

\section{Results and discussion}

\subsection{Characterization of the particle surface and dispersion level}

Figure 2 shows the surface chemistry of four types of nanosilica, i.e. A200, R312, R805, R974, using XPS. The signal ratio of $\mathrm{C}(1 \mathrm{~s})$ to $\mathrm{O}(1 \mathrm{~s})$ is 0.76 for unmodified nanoparticles (A200). The ratios are relatively higher for the modified ones, which are 1.86, 1.69 and 3.60 for R312, R805 and R974, respectively. The high intensity ratio of carbon signal indicates the presence of organic species for surface modified silica [23]. Note that the signal of C(1s) for A200 is probably due to the presence of carbon impurity in these fillers, such as carbon dioxide, according to the literature [25].The shift of O (1s) signals (Figure 2b) and Si (2p) signals (Figure 2c) of modified silica (R312, R805 and R974, respectively) toward lower binding energy indicates the silane coupling reaction has done on the surface of silica [24]. It can be seen from Figure 2a that as the intensity of carbon signals increases, the intensity of silicon and oxygen signals reduce accordingly, indicating the coating of silane on the silica surface, which may offer nice interfacial properties.

The SEM micrographs in Figure 3 show the dispersion levels of nanosilicas in LDPE on the fracture surface of nanocomposites. All the nanosilicas (A200, R312, R805, R974) are dispersed well with no big 

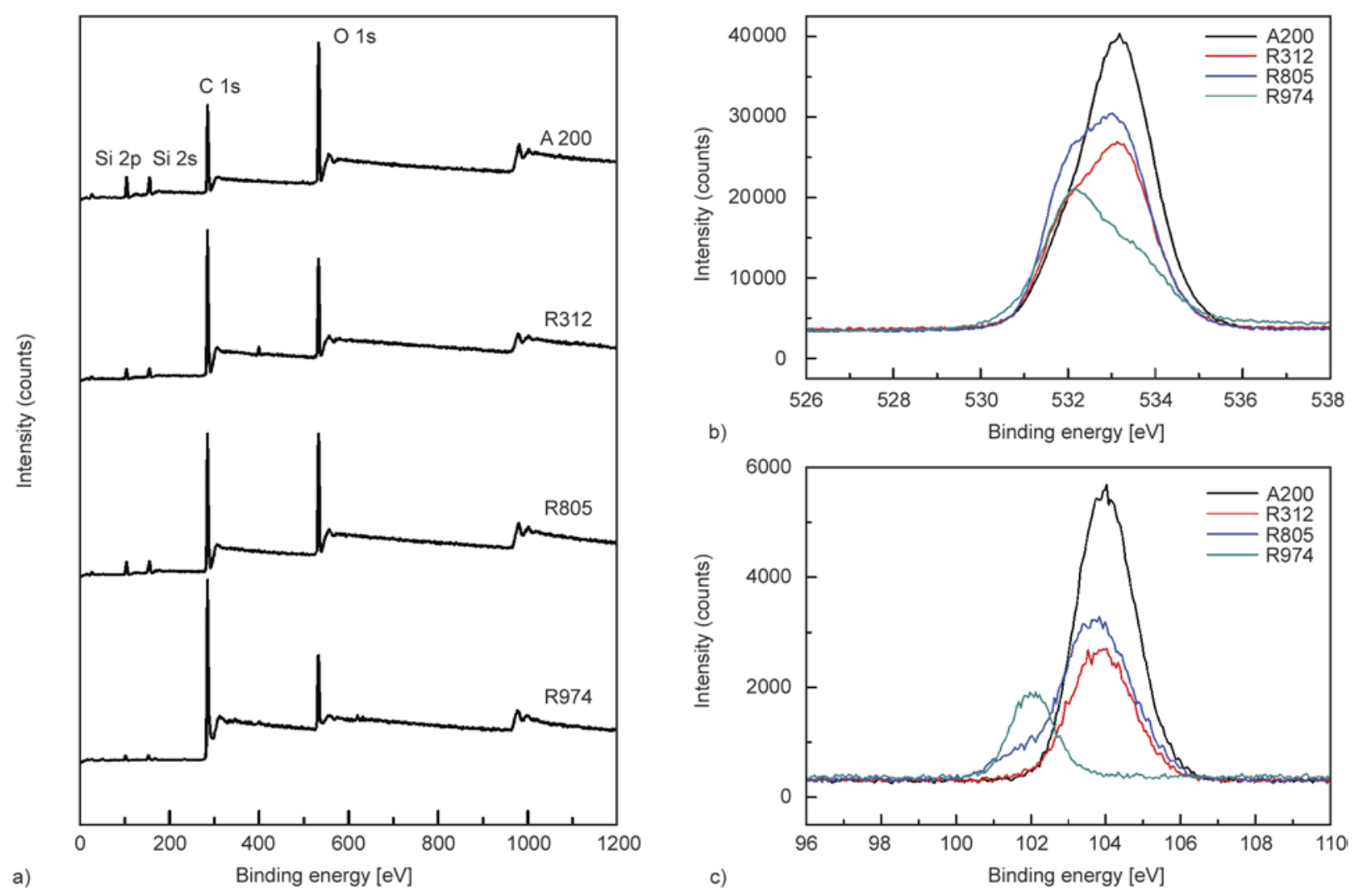

Figure 2. XPS spectra of (a) the silica nanoparticles used and comparison of four types of silica on (b) oxygen signals and (c) silicon signals

agglomerates in the nanocomposites. The arrows in Figure 3 indicate some cavitations between nanoparticles and polymer matrix, suggesting the relatively weak interfacial adhesion. This situation seems more obvious for the unmodified nanoparticles (A200) than the other modified nanoparticles (R312, R805, R974). This means the chemical surface modification does improve the interfacial adhesion.

\subsection{Dielectric breakdown strength}

The dielectric breakdown strength of the nanocomposites is analyzed within the framework of Weibull statistics. The Weibull parameters, $\alpha$ and $\beta$ (representing the characteristic dielectric breakdown strength and shape parameter), are shown in the insert table in Figure 4. $\alpha$ is found to be strongly affected by the filler modification in the nanocomposite samples and the voltage ramping rate [5]. Addition of nanosilica particles reduce $\alpha$ values of the LDPE polymers, which is likely due to the more defects in the composite samples that result in charge accumulation and partial discharge. The defects are formed due to the relatively weak interface, voids as well as the larger aggregates. Comparatively, the modified nanoparticles show the relatively higher $\alpha$ values than the unmodified ones, owing to the improved interface, good dispersion level and smaller aggregates [26]. In addition, $\alpha$ values of the samples increase as the voltage ramping rate increases from $500 \mathrm{~V} / \mathrm{s}$ to $2 \mathrm{kV} / \mathrm{s}$ due to the viscoelastic behavior of LDPE polymer.

\subsection{Space charge}

Figure 5 shows the PEA curves of the neat LDPE and nanocomposite samples (silica content $=5 \mathrm{wt} \%$ ) tested at an applied electric field of $40 \mathrm{kV} / \mathrm{mm}$. The curves show the evaluation of space charges in the samples. After applying the electric field for $0.5 \mathrm{~min}$, the space charges are found to accumulate near the electrodes. After applying the electric field for $10 \mathrm{~min}$, the space charges obviously diffuse to the middle of the sample, as indicated by black arrows in Figure 5 [27]. Nevertheless, the space charge injection has been significantly inhibited for the modified silica nanocomposites. The space charge accumulation in the middle of the sample is reduced, while only a small amount of charge is found near the electrodes. Interestingly, the heterocharges are found near the anode of R974/LDPE, as shown by the red arrow in Figure 5, which may originate from the chemistry nature of the silica surface. The outer elec- 


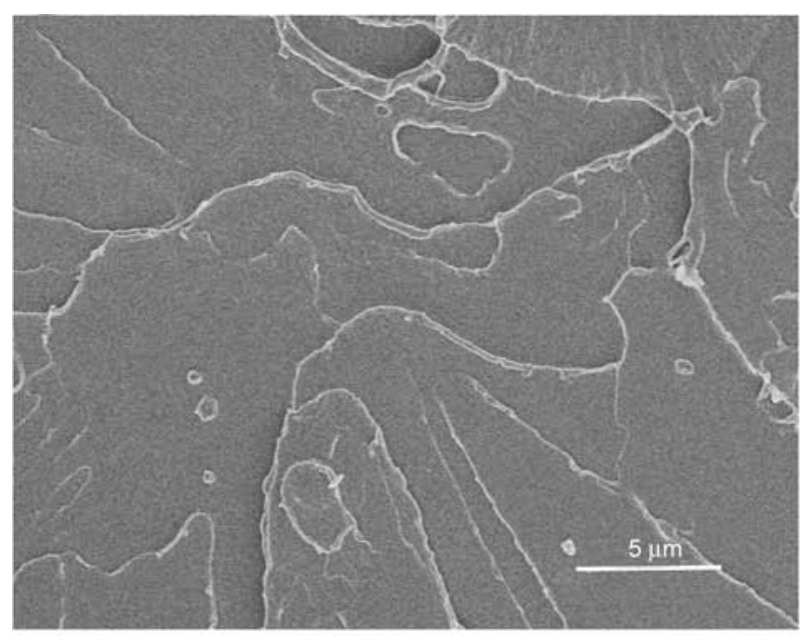

a)

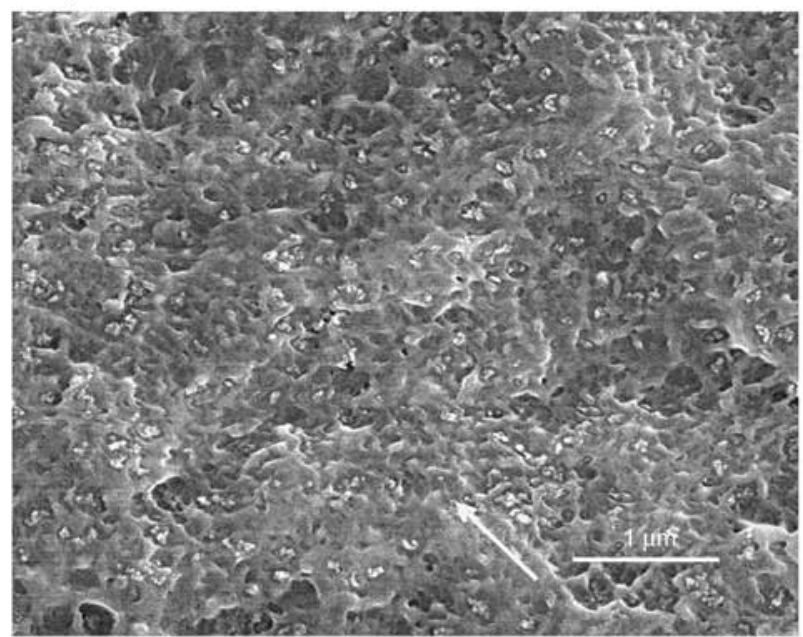

c)

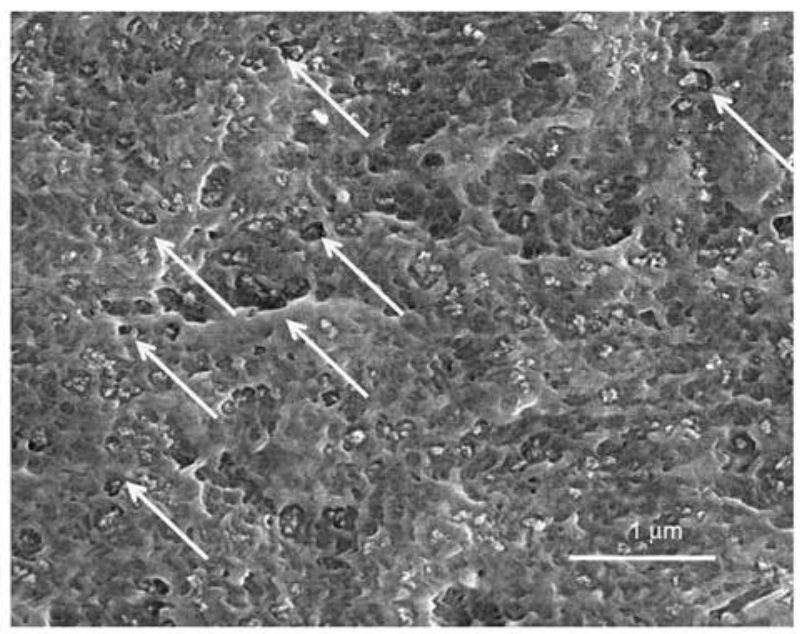

b)

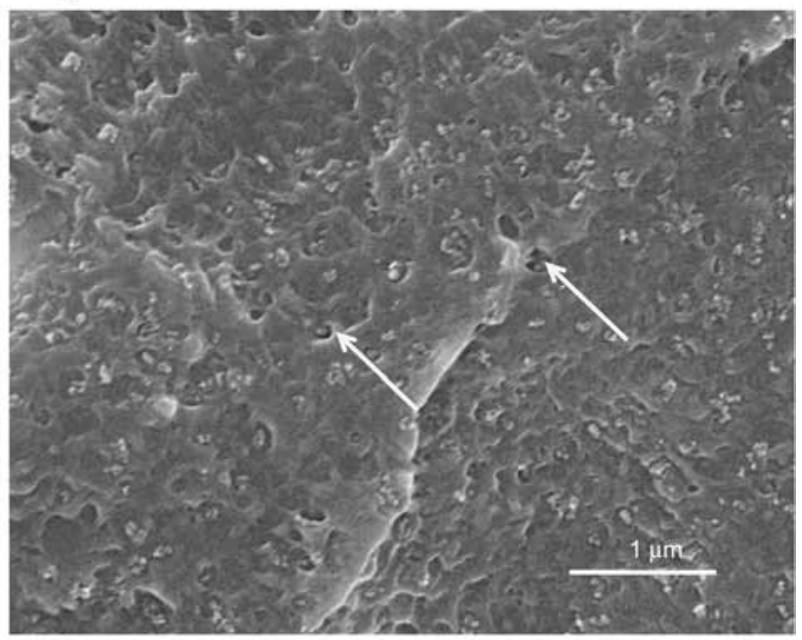

d)

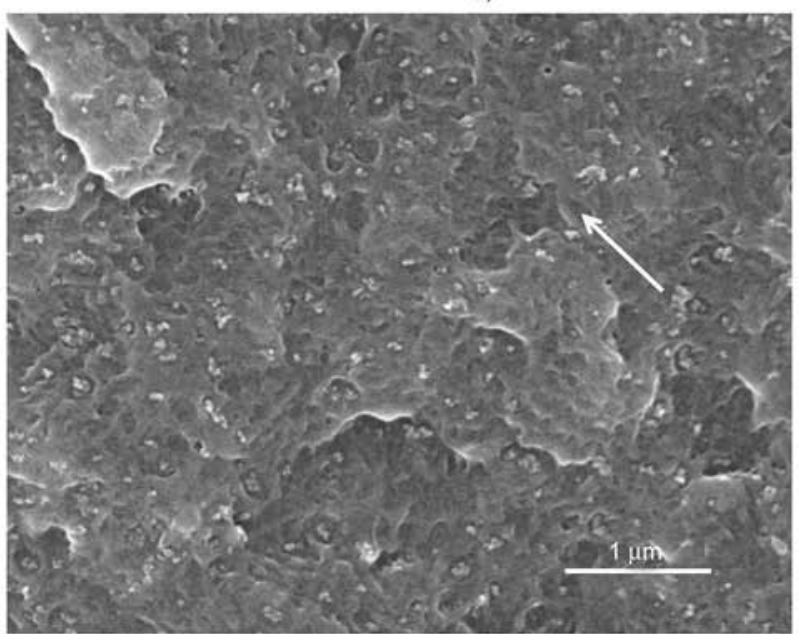

e)

Figure 3. SEM micrographs of the fracture surfaces of composites filled with $5 \mathrm{wt} \%$ silica nanoparticles: (a) LDPE, (b) A200/LDPE, (c) R312/LDPE, (d) R805/LDPE, and (e) R974/LDPE

trons of chlorine originating from dimethyldichlorosilane coated on R974 are far from the nucleus. It is susceptible to deform and polarize due to the applied electric field. The polarized reactions are particularly likely to occur at the anode. Changes in the distribution of space charge caused by surface modification are also reported by Huang et al. [9] and Ma et al. [28]. As the space charge is the initiator of aging, it is very meaningful to do the filler surface modification to improve its interfacial adhesion and dispersion in the matrix, in order to suppress space charge injection. 

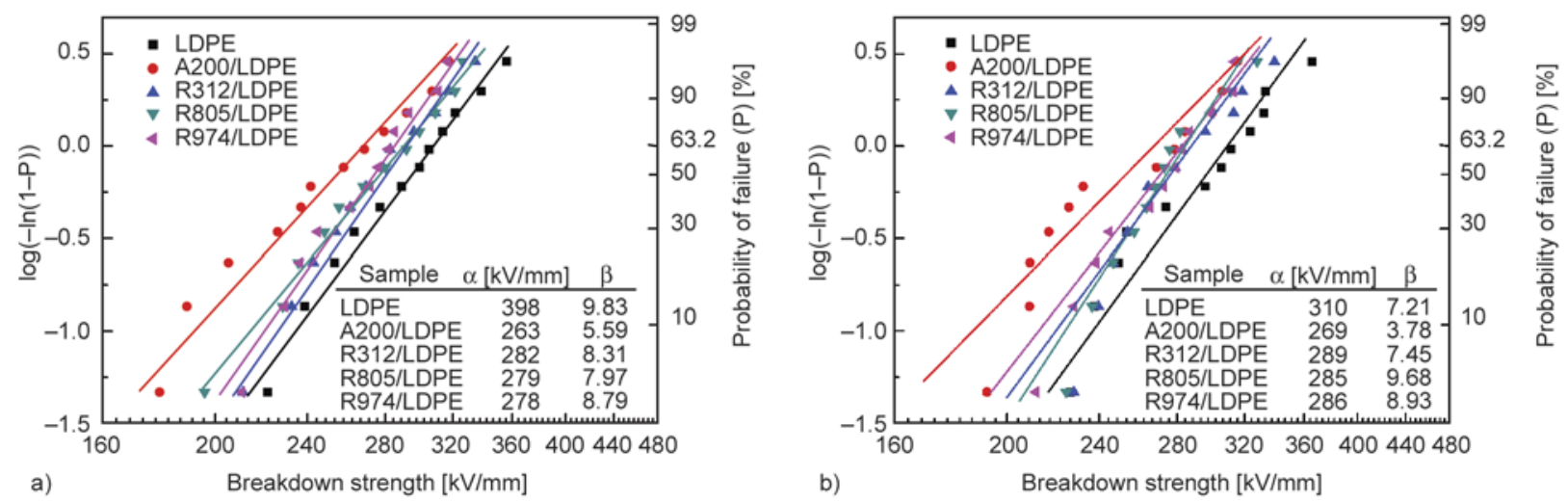

Figure 4. Weibull probability plots of DC breakdown strength of LDPE and its nanocomposite films at voltage ramping rate of (a) $500 \mathrm{~V} / \mathrm{s}$ and (b) $2 \mathrm{kV} / \mathrm{s}$

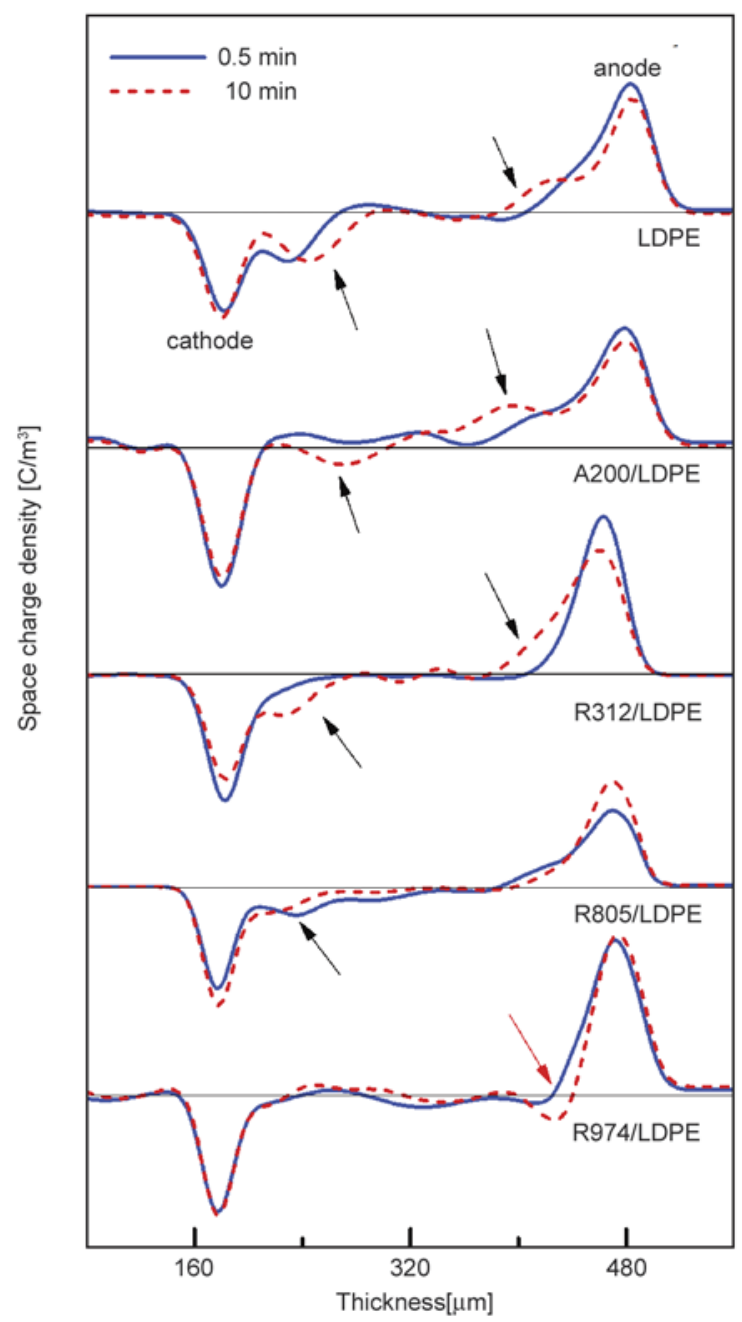

Figure 5. Space charge distribution of neat LDPE and its nanocomposites with the thickness of $300 \mu \mathrm{m}$

\subsection{Dielectric properties}

Figure 6 shows the dielectric constant and loss tangent $(\tan \delta)$ as a function of frequency at $25^{\circ} \mathrm{C}$ for the neat LDPE and nanocomposites. At low frequencies the dielectric constant of LDPE increases strongly with decreasing frequencies up to very high values
(Figure 6a) which cannot be explained by molecular relaxation processes. Such a behavior is a clear sign of electrode polarization, which originates from the blocking of charge carriers at the sample/electrode interface [29]. Medjdoub et al. [30] show similar results of LDPE appears at a low frequency. However, they consider this reflects conductivity effects due to free charge motion within the material. Moreover, at low frequencies the dipoles have sufficient time to align with the field before it changes direction giving rise to high permittivity. At high frequencies the dipoles do not have time to align before the field changes direction and the permittivity is lower [31]. The addition of A200 make permittivity of LDPE increase in the $1-1000 \mathrm{~Hz}$ range, but decrease in the $10000-100000 \mathrm{~Hz}$ range, while the permittivities of R312/LDPE, R805/LDPE and R974/LDPE all reduce to different extents (the insert of Figure 6a), indicating that the charge carriers movement was inhibited in the functionalized nanocomposites [32]. Moreover, the slope of the dielectric loss of functionalized nanocomposites is lower than A200/ LDPE (Figure 6b), suggesting that the conducting sheath present in the case of functionalized nanocomposites is less-conducting according to the O'Konski's model [33]. By this model, an induced polarization occurs at the polar ends of the particle by the applied electric field. Then charge carriers are efficiently transferred around the interface and become the conducting sheath [30]. This will lead to a permittivity higher than the particle itself. It is interesting to find that there is a relaxation peak in the range of $1000-100000 \mathrm{~Hz}$ in A200/LDPE, indicating changes of the LDPE molecular structure. A200 disrupt the original crystallization process of LDPE, resulting in more free volume, while the poor inter- 

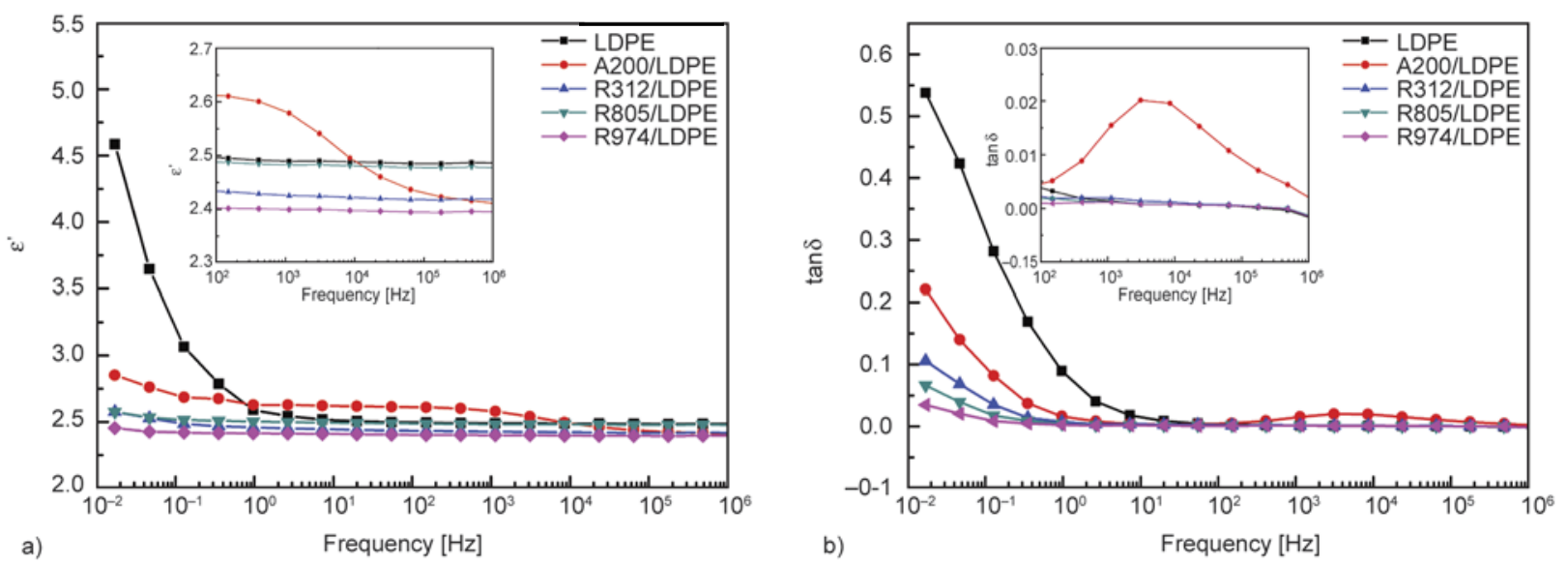

Figure 6. Dielectric constant (a) and loss tangent (b) for neat LDPE and the nanocomposites

face also introduces more defects, the relaxation of the polymer occurs [34].

\subsection{Polarization current and volume resistivity}

Figure 7 shows polarization currents and short-circuit currents measured for $5 \mathrm{~min}$. Both and short-circuit currents decrease exponentially with time, and subsequently reach an equilibrium value. LDPE needs $150 \mathrm{~s}$ to reach the equilibrium value of polarization currents, while only $20 \mathrm{~s}$ for nanocomposite (Figure 7a), and the initial value, equilibrium value of polarization current and short-circuit current of LDPE are much larger than those of nanocomposite. It could be indicated that a large amount of charges inject into and go through the LDPE. However, the nanosilica can inhibit the charges to inject into the interior of nanocomposite, and make most of charges gather on the surface of the sample [35]. It seems that the addition of nanosilica decrease the carrier mobility of nanocomposite. Meanwhile, the volume resistivity are $3.74 \times 10^{17}, 7.53 \times 10^{17}, 6.88 \times 10^{17}$, $7.12 \times 10^{17} \Omega \cdot \mathrm{cm}$ for A200/LDPE, R312/LDPE,

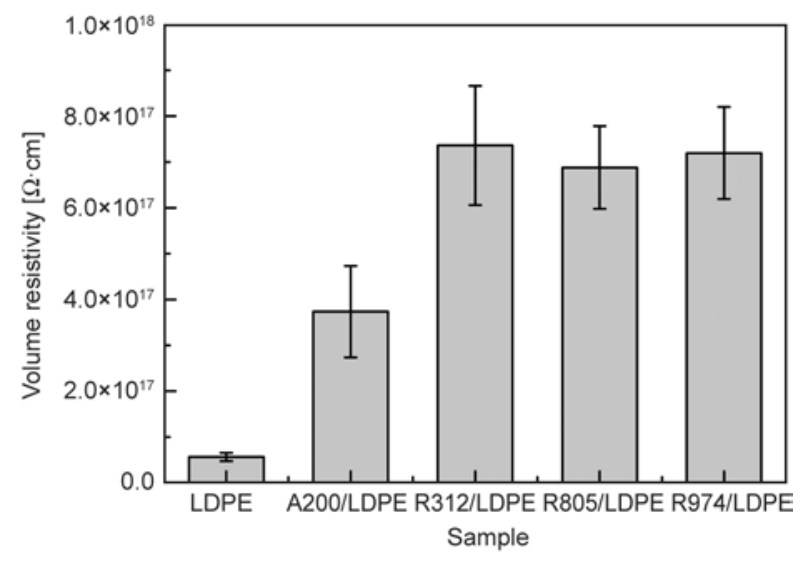

Figure 8. Volume resistivity at $20^{\circ} \mathrm{C}$ of neat LDPE and its nanocomposites

R805/LDPE, R974/LDPE respectively, about one order of magnitude larger than that of LDPE $\left(5.65 \times 10^{16} \Omega \cdot \mathrm{cm}\right)$ as shown in Figure $8[36]$.

\subsection{Carrier mobility}

The current density-voltage $(J-V)$ curves are obtained from the equilibrium value of polarization current at different voltages (Figure 9). It is consistent with
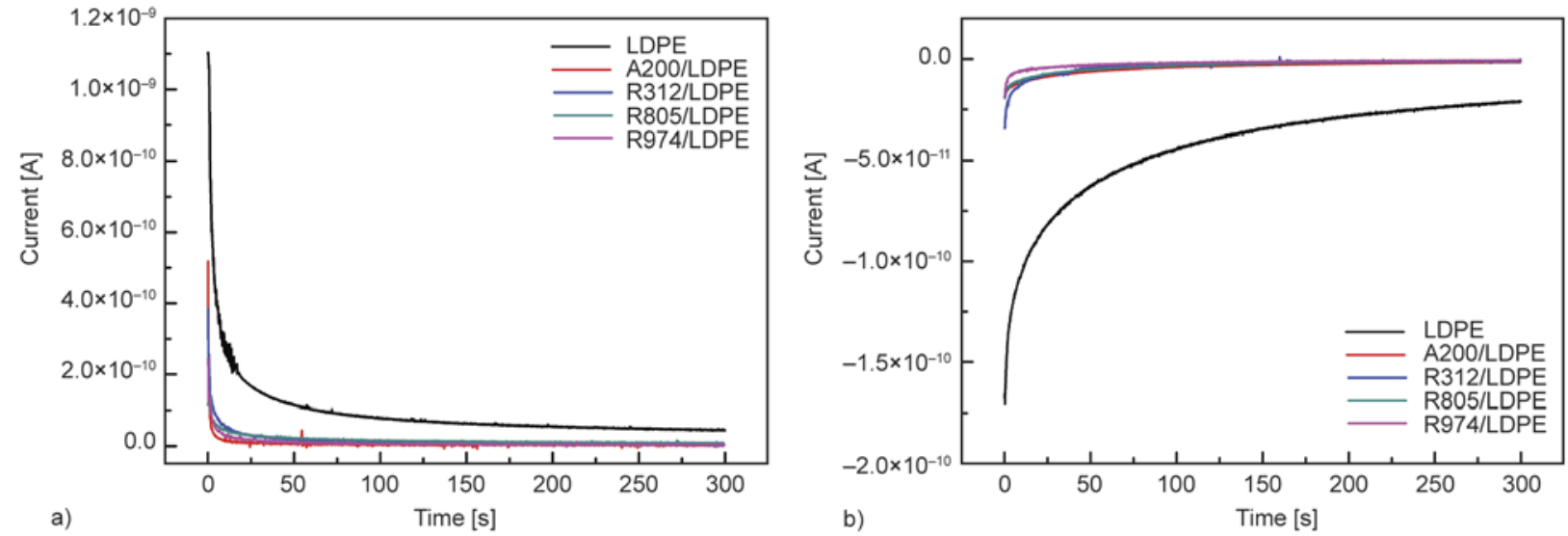

Figure 7. Polarization currents measured (a) at $1000 \mathrm{~V}$ and (b) in a short-circuit 
the well-known Mott and Gurney equation [37]. At low applied voltages the $J-V$ characteristics may follow Ohm's law (Equation (1)):

$$
J=q p_{0} \mu_{\mathrm{p}} \frac{V}{d}
$$

where $p_{0}$ is the density of thermally generated free carriers inside the sample, $\mu_{\mathrm{p}}$ is the carrier mobility and $d$ is the thickness of the sample. So we can use the slope of the linear fit, $k_{1}=q p_{0} \mu_{\mathrm{p}} / d$, to calculate the volume resistivity of the materials. The results are shown in the Table 2, which are consistent with the experimental results.

Due to the increased space charge, quadratic relationship of $J-V$ curves fitting are obtained (Figure 9) at high applied voltages as shown by Equation (2):

$J=\frac{9}{8} \varepsilon_{\mathrm{r}} \varepsilon_{0} \mu_{\mathrm{p}} \frac{V^{2}}{d^{3}}$

where $\varepsilon_{\mathrm{r}}$ is the relative permittivity of the material, and $\varepsilon_{0}=8.854 \times 10^{-12} \mathrm{~F} / \mathrm{m}$, is the permittivity of vacuum. Then the carrier mobility $\mu_{0}$ are calculated from the fitting constants $k$, where Equation (3):

$k=\frac{9 \varepsilon_{\mathrm{r}} \varepsilon_{0} \mu_{\mathrm{p}}}{8 d^{3}}$

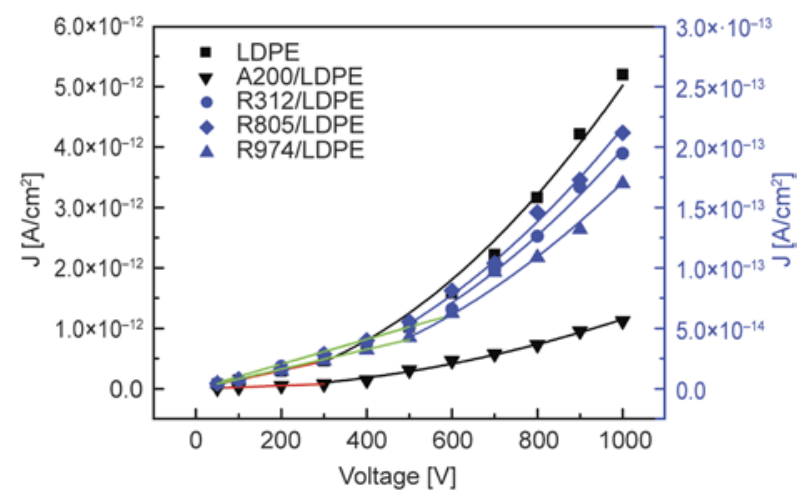

Figure 9. Current density-voltage $(J-V)$ curves from the equilibrium value of polarization current at different voltages

Table 2. The carrier mobility calculated by the fitting constants

\begin{tabular}{|l|c|c|c|c|}
\hline \multicolumn{1}{|c|}{ Sample } & $\mathbf{k}$ & $\begin{array}{c}\text { Carrier } \\
\mathbf{m o b i l i t y} \boldsymbol{\mu}_{\mathbf{p}} \\
{\left[\mathbf{c m}^{2} /(\mathbf{V} \cdot \mathbf{s})\right]}\end{array}$ & $\mathbf{k}_{\mathbf{l}}$ & $\begin{array}{c}\text { Volume } \\
\text { resistivity } \boldsymbol{\rho} \\
{[\mathbf{\Omega} \cdot \mathbf{c m}]}\end{array}$ \\
\hline $\mathrm{LDPE}$ & $5.02 \times 10^{-18}$ & $6.97 \times 10^{-12}$ & $1.52 \times 10^{-15}$ & $6.60 \times 10^{16}$ \\
\hline $\mathrm{A} 200 / \mathrm{LDPE}$ & $1.16 \times 10^{-18}$ & $1.61 \times 10^{-12}$ & $2.64 \times 10^{-16}$ & $3.81 \times 10^{17}$ \\
\hline $\mathrm{R} 312 / \mathrm{LDPE}$ & $1.98 \times 10^{-19}$ & $2.75 \times 10^{-13}$ & $1.02 \times 10^{-16}$ & $9.79 \times 10^{17}$ \\
\hline $\mathrm{R} 805 / \mathrm{LDPE}$ & $2.16 \times 10^{-19}$ & $3.00 \times 10^{-13}$ & $1.03 \times 10^{-16}$ & $9.74 \times 10^{17}$ \\
\hline $\mathrm{R} 974 / \mathrm{LDPE}$ & $1.71 \times 10^{-19}$ & $2.37 \times 10^{-13}$ & $8.15 \times 10^{-17}$ & $1.23 \times 10^{18}$ \\
\hline
\end{tabular}

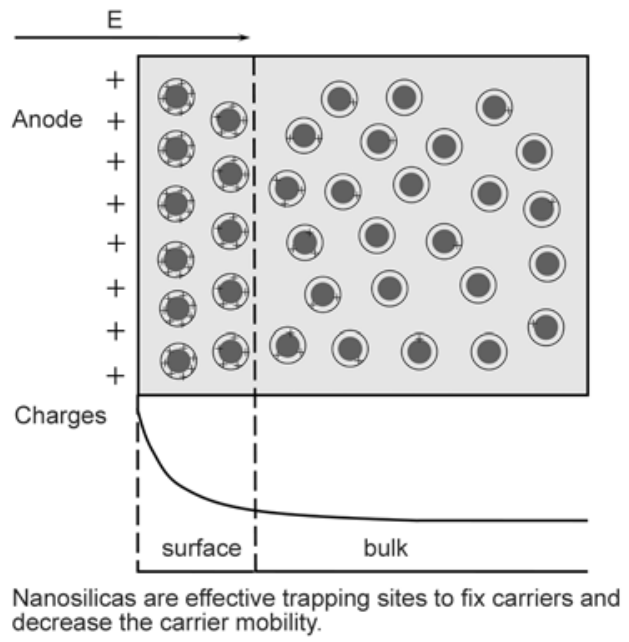

Figure 10. Schematic of the deep-trap hypothesis at high voltage in the insulating nanocomposites

As seen in Table 2, the carrier mobility of LDPE calculated by the above equations is $6.97 \times 10^{-12} \mathrm{~cm}^{2} /(\mathrm{V} \cdot \mathrm{s})$, which is comparable to published values [38, 39]. The addition of silica decreases the carrier mobility of composites, especially the silica modified by silane coupling agent, about an order of magnitude.

As the trapping model of 'induced dipole polarization' proposed by Takada, the potential well induced by nanoparticles is much deeper than that induced by chemical defects [10]. It makes the nanosilica become effective trapping site to fix carriers and decrease the carrier mobility. As illustrated in Figure 10, charges injected from electrodes generate in the deep trap induced by the nanosilica after electric voltage applied. The charges are difficult to move and accumulate near the electrodes to produce an additional electric potential reversed to the applied voltage. Therefore the potential difference near the electrode becomes small. It inhibits the dissociation of small molecule and prevents further injection of the charges. Therefore, the space charge inside the sample is reduced.

\section{Conclusions}

Bare silica (A200) and silane modified nanosilica (R312, R805 and R974) were incorporated to LDPE using a melt-mixing approach, to improve the dielectric properties of silica/LDPE nanocomposites. SEM revealed that modified nanosilicas were dispersed more evenly in the matrix than the unmodified ones. All nanosilicas lowered the space charge injection and accumulation, increased the volume resistivity, but decreased the dielectric breakdown strength of the 
LDPE. The surface modified silica/LDPE nanocomposites showed relatively higher dielectric breakdown strength, than the unmodified ones. It was found from polarization currents and short-circuit currents analysis that nanosilica prevented further injection of charges from electrodes into samples. The carrier mobility of modified silica/LDPE nanocomposites calculated from $J-V$ curves was about 5 times lower than those of unmodified ones, more than one order of magnitude lower than neat LDPE. The results obtained confirmed that the surface modification of nanoparticles was very necessary for improving the insulating properties of LDPE polymer.

\section{Acknowledgements}

The authors are grateful for the support by the National High Technology Research and Development Program of China (863 program, Grant No. 2013AA031803) and a key international collaboration project (Grant No. 2011DFR 50200 ) of the Ministry of Science and Technology of China.

\section{References}

[1] Hussain F., Hojjati M., Okamoto M., Gorga R. E.: Review article: Polymer-matrix nanocomposites, processing, manufacturing, and application: An overview. Journal of Composite Materials, 40, 1511-1575 (2006). DOI: $10.1177 / 0021998306067321$

[2] Pyun J., Matyjaszewski K.: Synthesis of nanocomposite organic/inorganic hybrid materials using controlled/ 'living' radical polymerization. Chemistry of Materials, 13, 3436-3448 (2001). DOI: $10.1021 / \mathrm{cm} 011065 \mathrm{j}$

[3] Sayari A., Hamoudi S.: Periodic mesoporous silicabased organic-inorganic nanocomposite materials. Chemistry of Materials, 13, 3151-3168 (2001). DOI: $10.1021 / \mathrm{cm} 0110391$

[4] Nelson J. K., Hu Y., Thiticharoenpong J.: Electrical properties of $\mathrm{TiO}_{2}$ nanocomposites. in '2003 Annual Report Conference on Electrical Insulation and Dielectric Phenomena. Albuquerque, USA ‘ 719-722 (2003). DOI: $10.1109 /$ ceidp.2003.1254955

[5] Roy M., Nelson J. K., MacCrone R. K., Schadler L. S., Reed C. W., Keefe R., Zenger W.: Polymer nanocomposite dielectrics-the role of the interface. IEEE Transactions on Dielectrics and Electrical Insulation, 12, 629-643 (2005). DOI: $10.1109 /$ tdei.2005.1511089

[6] Smith R. C., Liang C., Landry M., Nelson J. K., Schadler L. S.: The mechanisms leading to the useful electrical properties of polymer nanodielectrics. IEEE Transactions on Dielectrics and Electrical Insulation, 15, 187-196 (2008). DOI: $10.1109 /$ t-dei.2008.4446750
[7] Calebrese C., Le H., Schadler L. S., Nelson J. K.: A review on the importance of nanocomposite processing to enhance electrical insulation. IEEE Transactions on Dielectrics and Electrical Insulation, 18, 938-945 (2011). DOI: $10.1109 /$ tdei.2011.5976079

[8] Tanaka T., Montanari G. C., Mulhaupt R.: Polymer nanocomposites as dielectrics and electrical insulation-perspectives for processing technologies, material characterization and future applications. IEEE Transactions on Dielectrics and Electrical Insulation, 11, 763-784 (2004).

DOI: $10.1109 /$ tdei.2004.1349782

[9] Huang X., Jiang P., Yin Y.: Nanoparticle surface modification induced space charge suppression in linear low density polyethylene. Applied Physics Letters, 95, 242905 (2009).

DOI: $10.1063 / 1.3275732$

[10] Takada T., Hayase Y., Tanaka Y., Okamoto T.: Space charge trapping in electrical potential well caused by permanent and induced dipoles for LDPE/MgO nanocomposite. IEEE Transactions on Dielectrics and Electrical Insulation, 15, 152-160 (2008).

DOI: 10.1109/t-dei.2008.4446746

[11] Yin Y., Chen J., Yang J., Xiao D., Tu D., Yin R., Qian H.: Effect of space charge in nanocomposite of LDPE/ $\mathrm{TiO}_{2}$. in 'Proceedings of the $7^{\text {th }}$ International Conference on Properties and Applications of Dielectric Materials. Nagoya, Japan' Vol. 3, 913-916 (2003).

DOI: 10.1109/ICPADM.2003.1218570

[12] Yang J-M., Wang X., Zheng C-J., Zhao H., Lei Q-Q.: DC conduction properties of $\mathrm{SiO}_{2} / \mathrm{LDPE}$ Nanocomposite. in ' $10^{\text {th }}$ IEEE International Conference on the Properties and Applications of Dielectric Materials (ICPADM), Bangalore, India' 1-4 (2012).

DOI: 10.1109/ICPADM.2012.6318950

[13] Wang W., Li S., Tang F., Li J.: Characteristics on breakdown performance of polyethylene/silica dioxide nanocomposites. in '2012 Annual Report Conference on Electrical Insulation and Dielectric Phenomena. Montreal, Canada' 521-524 (2012).

DOI: $10.1109 /$ CEIDP.2012.6378834

[14] Schmidt D., Shah D., Giannelis E. P.: New advances in polymer/layered silicate nanocomposites. Current Opinion in Solid State and Materials Science, 6, 205-212 (2002). DOI: $10.1016 / \mathrm{s} 1359-0286(02) 00049-9$

[15] Lewis T. J.: Nanometric dielectrics. IEEE Transactions on Dielectrics and Electrical Insulation, 1, 812-825 (1994). DOI: $10.1109 / 94.326653$

[16] Tanaka T.: Dielectric nanocomposites with insulating properties. IEEE Transactions on Dielectrics and Electrical Insulation, 12, 914-928 (2005).

DOI: $10.1109 /$ tdei.2005.1522186 
[17] Tanaka T., Kozako M., Fuse N., Ohki Y.: Proposal of a multi-core model for polymer nanocomposite dielectrics. IEEE Transactions on Dielectrics and Electrical Insulation, 12, 669-681 (2005).

DOI: $10.1109 /$ tdei.2005.1511092

[18] Geng Y., Liu M. Y., Li J., Shi X. M., Kim J. K.: Effects of surfactant treatment on mechanical and electrical properties of CNT/epoxy nanocomposites. Composites Part A: Applied Science and Manufacturing, 39, 18761883 (2008). DOI: 10.1016/j.compositesa.2008.09.009

[19] Siqueira G., Bras J., Dufresne A.: Cellulose whiskers versus microfibrils: Influence of the nature of the nanoparticle and its surface functionalization on the thermal and mechanical properties of nanocomposites. Biomacromolecules, 10, 425-432 (2009).

DOI: $10.1021 / \mathrm{bm} 801193 \mathrm{~d}$

[20] Roy M., Nelson J. K., MacCrone R. K., Schadler L. S.: Candidate mechanisms controlling the electrical characteristics of silica/XLPE nanodielectrics. Journal of Materials Science, 42, 3789-3799 (2007).

DOI: $10.1007 / \mathrm{s} 10853-006-0413-0$

[21] Yan W., Han Z. J., Phung B. T., Ostrikov K.: Nanosilicas treated by cold atmospheric-pressure plasmas improve the dielectric performance of organic-inorganic nanocomposites. Acs Applied Materials and Interfaces, 4, 2637-2642 (2012).

DOI: $10.1021 / \mathrm{am} 300300 \mathrm{f}$

[22] Huang X., Zheng Y., Jiang P., Yin Y.: Influence of nanoparticle surface treatment on the electrical properties of cycloaliphatic epoxy nanocomposites. IEEE Transactions on Dielectrics and Electrical Insulation, 17, 635-643 (2010). DOI: $10.1109 /$ tdei.2010.5448121

[23] Laruelle G., Parvole J., Francois J., Billon L.: Block copolymer grafted-silica particles: A core/double shell hybrid inorganic/organic material. Polymer, 45, 50135020 (2004).

DOI: 10.1016/j.polymer.2004.05.030

[24] Brito L., Fiolhais M.: Energetics of charge distributions. European Journal of Physics, 23, 427-432 (2002). DOI: $10.1088 / 0143-0807 / 23 / 4 / 306$

[25] Ray S., Bhowmick A. K.: Novel electron beam-modified surface-coated silica fillers: Physical and chemical characteristics. Journal of Applied Polymer Science, 83, 2255-2268 (2002).

DOI: $10.1002 / a p p .10240$

[26] Wang Z., Iizuka T., Kozako M., Ohki Y., Tanaka T.: Development of epoxy/BN composites with high thermal conductivity and sufficient dielectric breakdown strength part II-breakdown strength. IEEE Transactions on Dielectrics and Electrical Insulation, 18, 19731983 (2011).

DOI: $10.1109 /$ tdei.2011.6118635

[27] Nelson J. K., Fothergill J. C.: Internal charge behaviour of nanocomposites. Nanotechnology, 15, 586-595 (2004). DOI: 10.1088/0957-4484/15/5/032
[28] Ma D., Hugener T. A., Siegel R. W., Christerson A., Mårtensson E., Önneby C., Schadler L. S.: Influence of nanoparticle surface modification on the electrical behaviour of polyethylene nanocomposites. Nanotechnology, 16, 724-731 (2005). DOI: 10.1088/0957-4484/16/6/016

[29] Kremer F., Schönhals A.: Broadband dielectric spectroscopy. Springer, Berlin (2003).

[30] Medjdoub A., Boubakeur A., Lebey T.: Dielectric spectroscopy analysis behavior of low density polyethylene. in '2008 IEEE Conference on Electrical Insulation and Dielectric Phenomena, Québec, Canada' 517-520 (2008).

DOI: $10.1109 / C E I D P .2008 .4772907$

[31] Dang Z-M., Zhang Y-H., Tjong S-C.: Dependence of dielectric behavior on the physical property of fillers in the polymer-matrix composites. Synthetic Metals, 146, 79-84 (2004).

DOI: $10.1016 /$ j.synthmet.2004.06.011

[32] Takala M., Ranta H., Nevalainen P., Pakonen P., Pelto J., Karttunen M., Virtanen S., Koivu V., Pettersson M., Sonerud B., Kannus K.: Dielectric properties and partial discharge endurance of polypropylene-silica nanocomposite. Dielectrics and Electrical Insulation, IEEE Transactions on Dielectrics and Electrical Insulation, 17, 1259-1267 (2010). DOI: $10.1109 /$ tdei.2010.5539698

[33] O'Konski C. T.: Electric properties of macromolecules. $\mathrm{V}$. Theory of ionic polarization in polyelectrolytes. The Journal of Physical Chemistry, 64, 605-619 (1960). DOI: $10.1021 / \mathrm{j} 100834 \mathrm{a} 023$

[34] Nanda M., Chaudhary R. N. P., Tripathy D. K.: Dielectric relaxation of conductive carbon black reinforced chlorosulfonated polyethylene vulcanizates. Polymer Composites, 31, 152-162 (2010). DOI: $10.1002 / p c .20779$

[35] Nelson J. K., Hu Y.: Nanocomposite dielectrics - Properties and implications. Journal of Physics D: Applied Physics, 38, 213-222 (2005). DOI: $10.1088 / 0022-3727 / 38 / 2 / 005$

[36] Leroux C., Mur P., Rochat N., Rouchon D., Truche R., Reimbold G., Ghibaudo G.: Characterization and modeling of nanometric $\mathrm{SiO}_{2}$ dielectrics. Microelectronic Engineering, 72, 121-124 (2004). DOI: $10.1016 /$ j.mee.2003.12.049

[37] Kao K. C., Hwang W.: Electrical transport in solids with particular reference to organic semiconductors. Taylor and Francis, London (1981).

[38] Meunier M., Quirke N., Aslanides A.: Molecular modeling of electron traps in polymer insulators: Chemical defects and impurities. Journal of Chemical Physics, 115, 2876-2881 (2001). DOI: $10.1063 / 1.1385160$

[39] Anta J. A., Marcelli G., Meunier M., Quirke N.: Models of electron trapping and transport in polyethylene: Current-voltage characteristics. Journal of Applied Physics, 92, 1002-1008 (2002). DOI: $10.1063 / 1.1489714$ 